\title{
Dynamic characteristics of torus involute gear drive
}

Lei Liu

College of Mechanical and Electrical Engineering, Nanjing University of Aeronautics and Astronautics, Nanjing 210016, China

Ye-Ping Xiong

Faculty of Engineering and the Environment, University of Southampton, Southampton SO16 7QF, United Kingdom

\begin{abstract}
The torus involute gear drive originates from the involute spur gear drive, which is composed of a gear with convex teeth and the one with concave teeth. Previous researches of its mesh principle indicate that the torus involute gear can compensate large axial misalignments in parallel-shaft transmission, while its dynamic behavior has not been investigated comprehensively, or compared with that of the standard involute gear. This paper focuses on the dynamic performance of this type of gear. Considering the time variation of meshing stiffness, a 6-degree-of-freedom dynamics model of the torus involute gear pair is established, which counts in the effect of alternate meshing of single-double tooth pairs. Sliding friction in elastohydrodynamic lubrication is also included in the model. The numerical analysis for six cases is conducted, and the dynamic characteristics such as the dynamic transmission error, mechanical efficiency, sliding friction forces and minimum oil-film thickness are compared with those of the standard involute gear. The results show that, the torus involute gear drive exhibits good performances as the standard involute gear drive in transmission accuracy and mechanical efficiency, while, it has a better performance in lubrication condition. The study in this paper may lay theoretical foundations for practical application of the torus involute gears.
\end{abstract}

\section{Nomenclature}

$\begin{array}{ll}T_{\mathrm{p}} & \text { driving moment on pinion } \\ T_{\mathrm{g}} & \text { resisting moment on gear } \\ \omega_{\mathrm{p}} & \text { nominal pinion speed } \\ r_{\mathrm{bp}} & \text { radius of base circle of pinion } \\ \lambda & \text { base pitch } \\ t_{\mathrm{C}_{\mathrm{g}}}, t_{\mathrm{c}} & \text { duration for one mesh cycle } \\ t_{\mathrm{C}_{\mathrm{p}}} & \text { duration from start point to lowest point of single tooth contact }\end{array}$




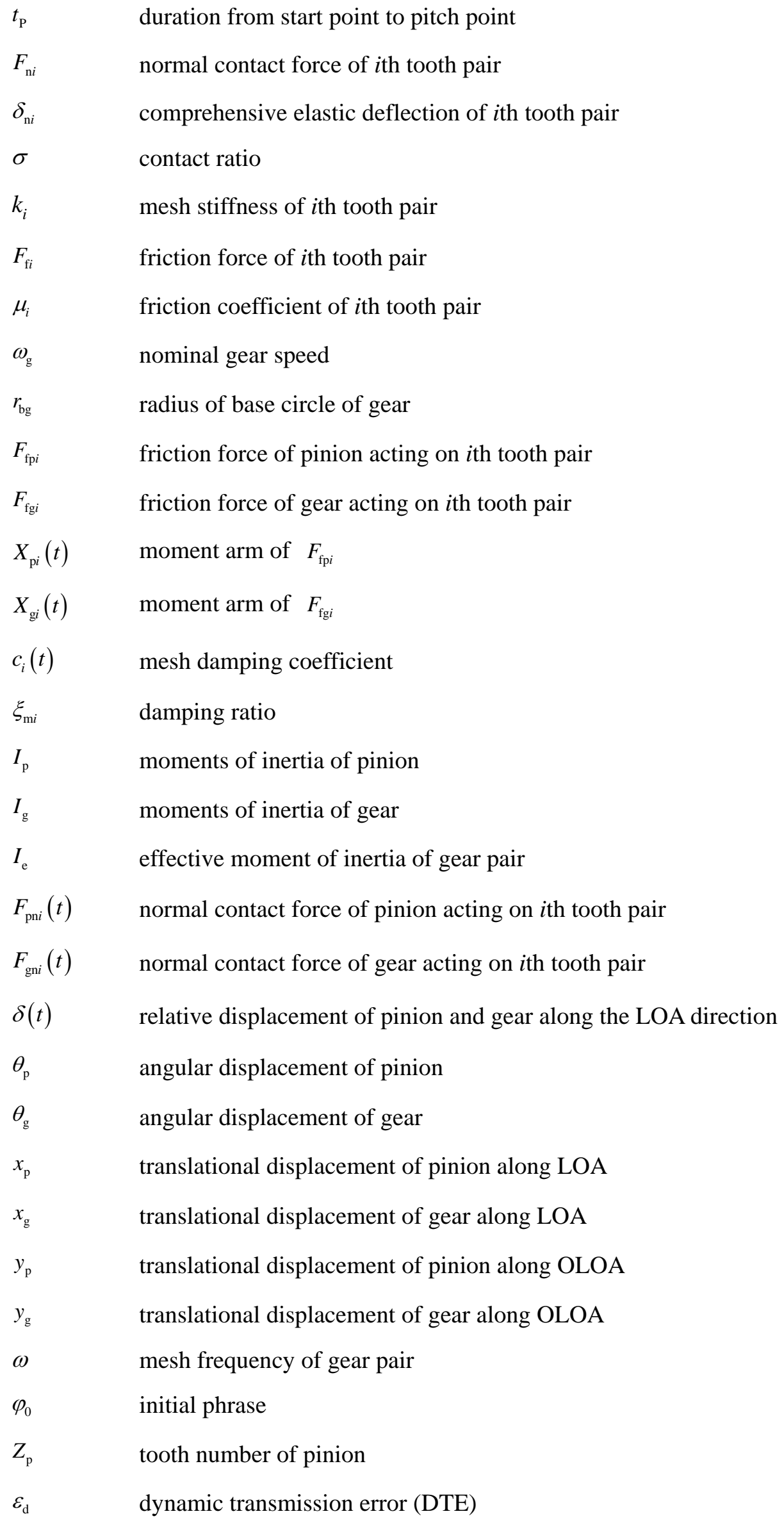




$\begin{array}{ll}K_{\mathrm{pBx}} & \text { shaft-bearing stiffness for pinion in LOA direction } \\ K_{\mathrm{gBx}} & \text { shaft-bearing stiffness for gear in LOA direction } \\ K_{\mathrm{pBy}} & \text { shaft-bearing stiffness for pinion in OLOA direction } \\ K_{\mathrm{gBy}} & \text { shaft-bearing stiffness for gear in OLOA direction } \\ \xi_{\mathrm{pBx}} & \text { damping ratio for pinion in LOA direction } \\ \xi_{\mathrm{gBx}} & \text { damping ratio for gear in LOA direction } \\ \xi_{\mathrm{pBy}} & \text { damping ratio for pinion in OLOA direction } \\ \xi_{\mathrm{gBy}} & \text { damping ratio for gear in OLOA direction } \\ P_{\mathrm{h}} & \text { Maximum Hertzian contact pressure in GPa } \\ v_{\mathrm{e}} & \text { entraining velocity in m/s } \\ v_{\mathrm{s}} & \text { sliding velocity in m/s } \\ s r & \text { slide-to-roll ratio } \\ \eta_{0} & \text { absolute viscosity at oil inlet temperature in cPs } \\ S & \text { RMS composite surface roughness in } \mu \mathrm{m} \\ R^{\prime} & \text { effective radius of curvature in m } \\ \chi & \text { mechanical efficiency } \\ v_{\mathrm{p}}, v_{\mathrm{g}} & \text { sliding velocity of pinion and gear } \\ F_{\mathrm{pri}} & \text { rolling friction force of pinion } \\ \alpha & \text { viscosity pressure coefficient } \\ E_{\mathrm{min}}^{\prime} & \text { reduced elastic modulus } \\ K^{\prime} & \text { dimensionless materials parameter }\end{array}$

\section{Introduction}

The torus involute gear drive ${ }^{[1]}$ is composed of a gear with convex teeth and the one with concave teeth, which can compensate large axial misalignments in parallel-shaft transmission (See Fig.1). Although studies of mathematical models and tooth contact analysis (TCA) have been implemented ${ }^{[2]}$, more sufficient proofs, especially dynamic performance, are needed to 
validate good meshing characteristics of the torus involute gear (TIG) transmission.

Theoretically, a precise and appropriate mathematical model is needed to analyze dynamic behaviors of a gear pair. The inner excitation source of gear systems includes time-varying mesh stiffness, transmission error and mesh impact. As the main excitation of motion along the off-line-of-action (OLOA), friction forces usually couple with backlash and time-varying mesh stiffness to make gear pairs act as nonlinear and time-varying systems. Additionally, power dissipation due to viscous shearing of the lubrication oil film along the tooth contact interfaces forms the main source of mesh viscous damping ${ }^{[3]}$. Houser ${ }^{[4]}$ experimentally demonstrated that the friction forces play a pivotal role in determining the load transmitted to the bearings and housing in the OLOA direction. Velex ${ }^{[5]}$ evaluated the effects of sliding friction, teeth shape deviations and time-varying mesh stiffness on spur and helical gears. He disclosed the potentially significant contribution of tooth friction to gear vibration and noise. Vaishya ${ }^{[6]}$ proposed a spur gear pair model with periodic tooth stiffness variations and sliding friction based on the assumption of equal load sharing among the teeth in contact. Song ${ }^{[7,8]}$ calculated the friction coefficient utilizing the empirical expression by Kelley ${ }^{[9]}$ and incorporated the sliding friction and realistic time-varying tooth stiffness into analytical spur and helical gear models. This work revealed that sliding friction has marginal effects on the dynamic transmission error of helical gears, as compared with spur gears. Feng ${ }^{[10]}$ established a time-varying friction coefficient model including the effect of mixed elastohydrodynamic lubrication and incorporated it into a time-varying dynamic model for right-angle hypoid and spiral bevel gears. Wang ${ }^{[11]}$ built a dynamic model of helical gear pair considering friction and multiple backlashes, and calculated the meshing efficiency with the formula of sliding friction coefficient by $\mathrm{Xu}^{[12]}$.

As the number of tooth pairs in mesh varies periodically in gearing, dynamic behavior of simultaneous meshing pairs are different. Although time variation of mesh stiffness or sliding friction is considered, most of the torsional vibration models ${ }^{[4 \sim 6][10][11]}$ above cannot provide dynamic characteristics of each meshing tooth pair, especially friction force and normal mesh force.

In view of tooth shape's complexity of the TIG and point-contact pattern, an efficient and accurate dynamic model is in great request, which can account for the effects of sliding friction, time-varying mesh stiffness, static transmission error and continuous alternate meshing. Therefore, the main motivation of this paper is to set up an accurate multi-degree-of-freedom analytical model in elastohydrodynamic lubrication to comprehend dynamic characteristics of the TIG.

\section{Review of torus involute gears}




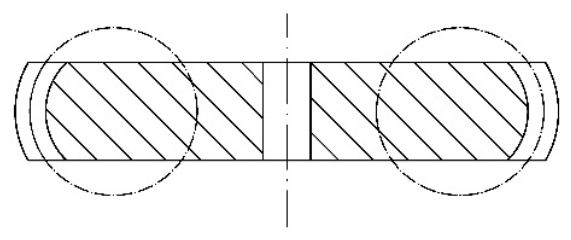

a. Convex gear

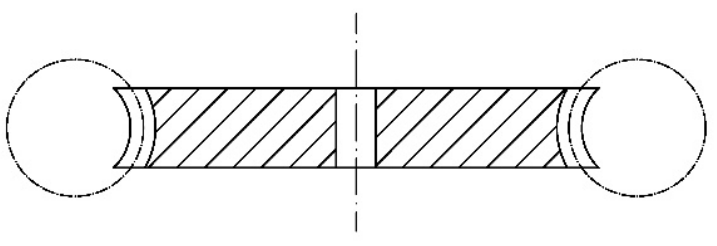

b. Concave gear

Fig. 1. Torus involute gears

As shown in Fig.1, each tooth of the TIG is symmetrical about the middle plane of face width. The tip surface or root surface is respectively an outer or inner torus generated by a circle centering at the intersection of the line parallel to the gear axis and the middle plane. Each flank of the cross-section along face width is still an involute profile generated from the same base circle. For the convex gear, tooth thickness on the reference circle gradually decreases from the middle to both ends of face width, whereas tooth thickness on the tip circle gradually increases. On the contrary, tooth thickness of the concave gear varies reversely. Whether the concave or convex gear, the flank on the middle section is still a standard spur gear profile. Essentially, the TIG is the spur gear with continuous shifting in the second order.

According to TCA of a TIG pair ${ }^{[2]}$, the concave and convex gears mesh in point contact, and all the contact points exist in the middle section if there is no installation error. As depicted in Fig. 2, either of the engaged tooth surfaces contacts tangentially with the imaginary rack cutter surface. At a generic meshing point, the normal vector of imaginary cutter surface, (also the common normal of engaged tooth surfaces) is in the middle section plane of engaged TIG surfaces. Thus the gearing of TIGs in the middle section can be viewed as the meshing of two standard involute spur gears. The difference lies in the contact area and contact pattern. Specifically, the TIGs mesh in point-contact, forming elliptical contacting regions.

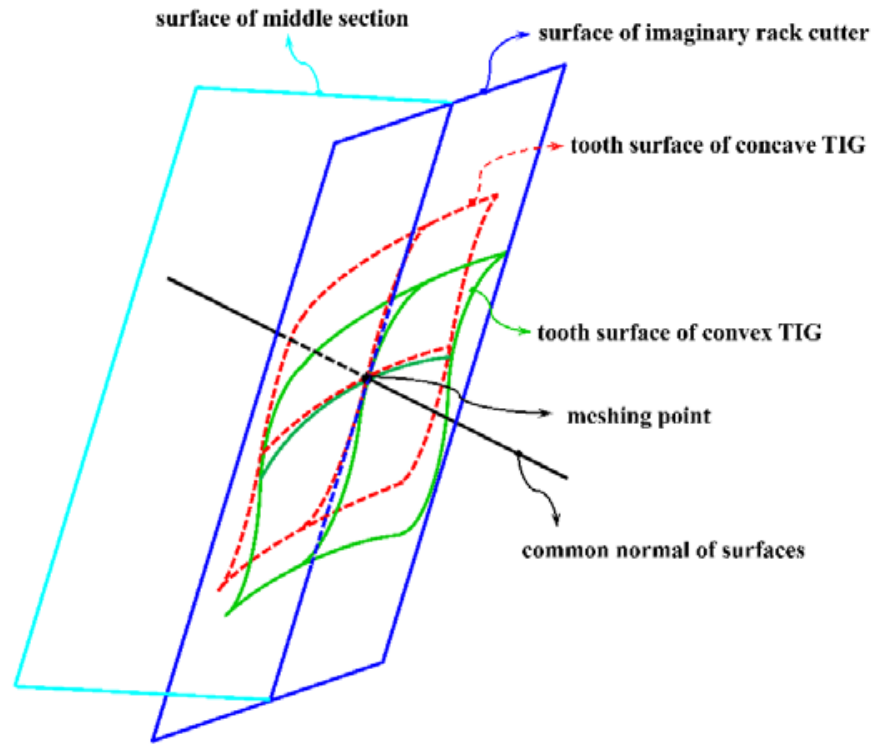


Fig. 2. Mesh of engaged TIG surfaces

\section{Mathematical model}

Generally speaking, the contact ratio of a gear transmission is not integer. The number of meshing pairs changes periodically. Consequently, the mesh stiffness also makes a cyclic change. Besides, the status of meshing pair varies with contact point, especially when the engaged tooth profiles pass through the pitch point. Hence transitions in key meshing events within a mesh cycle need to be determined for the construction of the stiffness function as well as calculation of sliding friction forces. Most of models in previous researches just treat the gear drive as a pair of wheels connected by a torsional spring without considering forces on each pair separately. Song ${ }^{[7]}$ analyzed the timing of key meshing events for a generic spur gear pair with non-integer contact ratio. Similarly, the contribution of Song applies to the TIG drive.

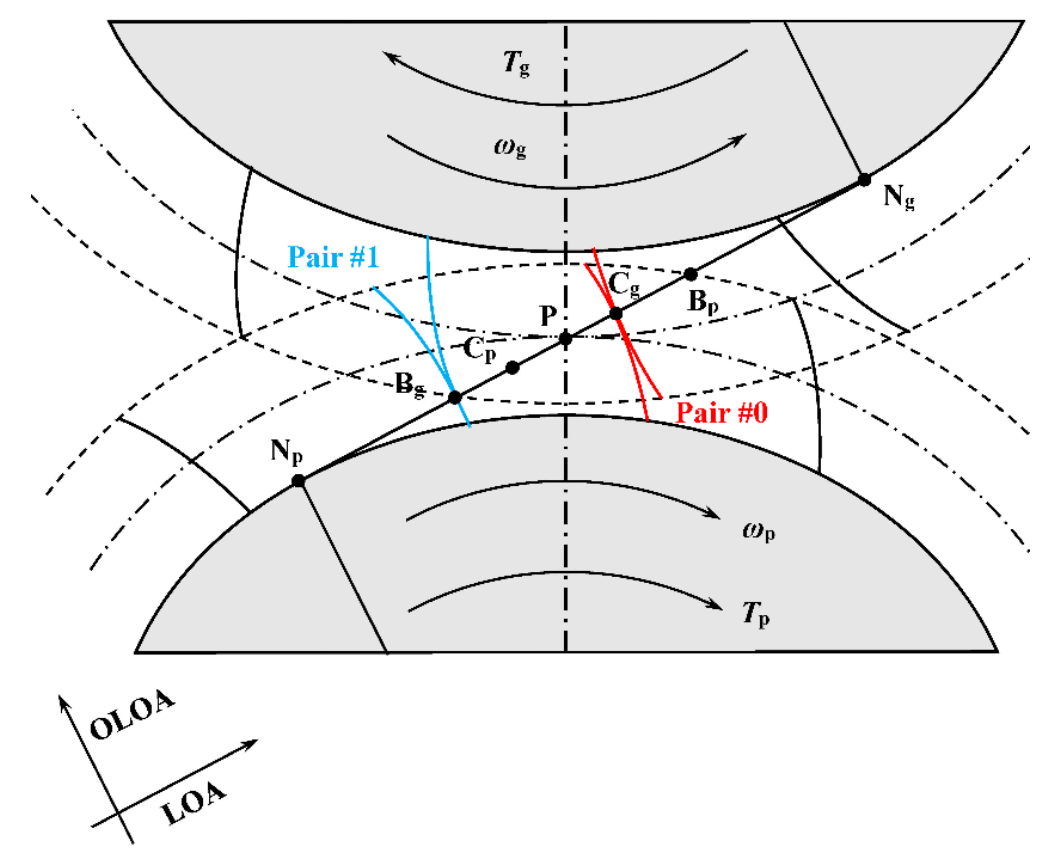

Fig. 3. Snap short of contact pattern (at $t=0$ ) in middle section of TIGs

As shown in Fig. 3, the driving moment $T_{\mathrm{p}}$ and resisting moment $T_{\mathrm{g}}$ are respectively applied to the pinion and gear, and $\omega_{\mathrm{p}}$ and $\omega_{\mathrm{g}}$ are their nominal angular velocity. The line of action (LOA) of gearing is $\mathrm{N}_{\mathrm{p}} \mathrm{N}_{\mathrm{g}}$, which is the common tangent of base circles. The intersection of tip circle of the gear and the LOA is point $\mathrm{B}_{\mathrm{g}}$, the start point of meshing. Point $\mathrm{B}_{\mathrm{p}}$, the intersection of tip circle of the pinion and the LOA, is the end point of meshing. Suppose at one moment tooth pair \#1 just comes into mesh at point $\mathrm{B}_{\mathrm{g}}$, and meanwhile the previous one, pair $\# 0$ is contacting at point $C_{g}$, the highest point of single tooth contact 
(HPSTC). As the gears rotate, when pair \#1 arrives at the lowest point of single tooth contact (LPSTC) of point $\mathrm{C}_{\mathrm{p}}$ at $t=t_{\mathrm{C}_{\mathrm{p}}}$, pair $\# 0$ separates at $\mathrm{B}_{\mathrm{p}}$. At $t=t_{\mathrm{p}}$, pair $\# 1$ passes through the pitch point $\mathrm{P}$, and the relative sliding velocity of engaged profiles is reversed, resulting in a reversal of the friction force, which incurs an impulse excitation to the system. Finally, pair $\# 1$ goes through point $\mathrm{C}_{\mathrm{g}}$ at $t=t_{\mathrm{C}_{\mathrm{g}}}=t_{\mathrm{c}}$, finishing one mesh cycle $\left(t_{\mathrm{C}_{\mathrm{g}}}\right)$. These key durations are defined as follows

$$
\begin{aligned}
& t_{\mathrm{C}_{\mathrm{g}}}=\frac{\lambda}{\omega_{\mathrm{p}} r_{\mathrm{bp}}} \\
& t_{\mathrm{C}_{\mathrm{p}}}=\frac{\overline{\mathrm{B}_{\mathrm{g}} \mathrm{C}_{\mathrm{p}}}}{\lambda} t_{\mathrm{C}_{\mathrm{g}}} \\
& t_{\mathrm{p}}=\frac{\overline{\mathrm{Bg}_{\mathrm{g}} \mathrm{P}}}{\lambda} t_{\mathrm{C}_{\mathrm{g}}}
\end{aligned}
$$

\subsection{Time varying mesh stiffness}

Due to complexity of tooth shape, it is difficult to calculate mesh stiffness of the TIG pair via the analytical method. So an 8-9-tooth finite element model (FEM) is created to compute the mesh stiffness. As depicted in Fig. 4, the preprocessing of the FEM is completed in commercial code Hypermesh according to the 3-D models.

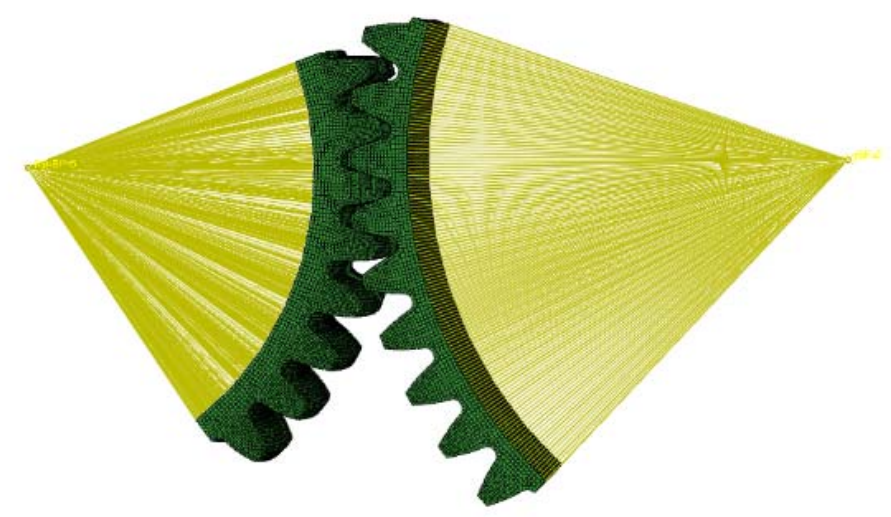

Fig. 4. 8-9-tooth finite model of TIG

In this $\mathrm{FEM}^{[13]}$, either of the engaged gears can only rotate about its own axis; Teeth are connected to a central node by massless rigid elements; The pinion has a constant angular velocity, and the braking torque $T_{\mathrm{g}}$ is applied to the gear. The contact algorithm is set to explicit and surface-surface contact. The dynamic finite element analysis is performed in commercial code Abaqus to obtain normal contact forces and comprehensive elastic deflection of the pinion. The results were verified by the analytical ones in reference [13]. Then the stiffness function of the ith meshing tooth pair is given by Eq. (4), where the "floor" function rounds the contact ratio $\sigma$ down to the nearest integer value. For a generic tooth pair, 
its mesh stiffness is as follows

$k_{i}(t)=\frac{F_{\mathrm{n} i}(t)}{\delta_{\mathrm{ni}}(t)}, \quad i=0,1, \ldots$, floor $(\sigma)$

For example, if $\sigma \in(1,2)$, for pair \#1, twenty contact points on the LOA are chosen to compute mesh stiffness with (4). The corresponding results are shown in Tab.1.

Tab. 1

Mesh

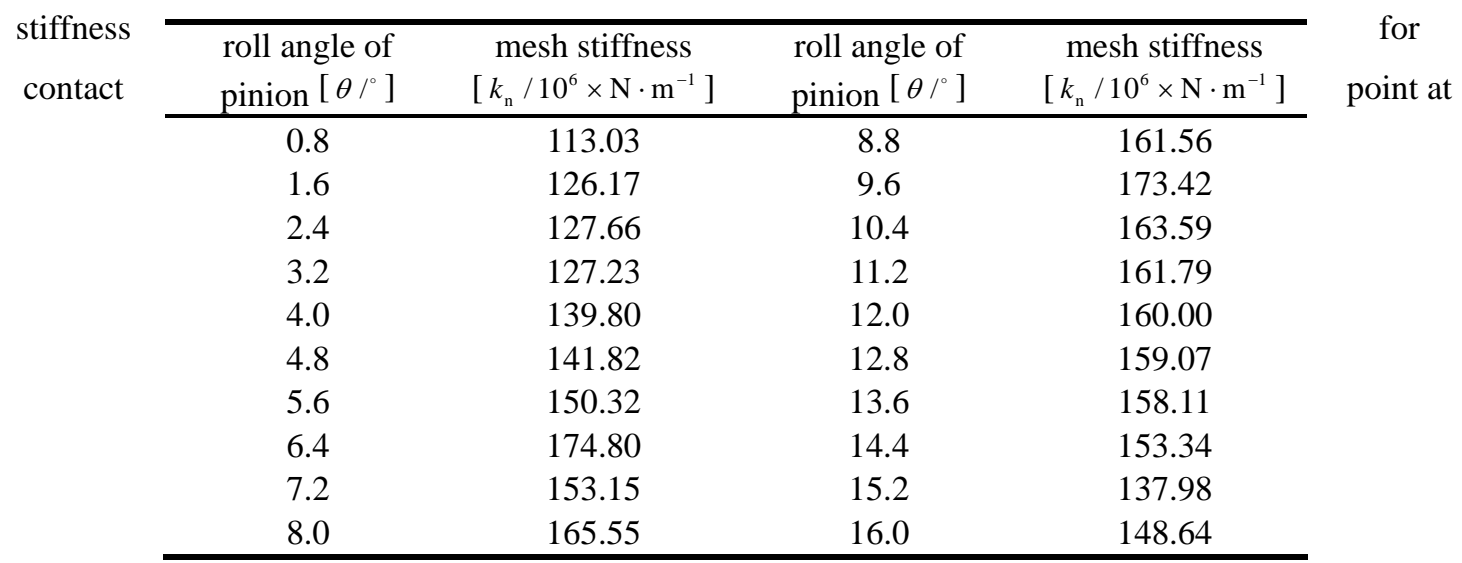

$T_{\mathrm{g}}=100 \mathrm{~N} \cdot \mathrm{m}$

Based on the data in above table, the mesh stiffness can be expressed as the function of time by polynomial fitting. Considering the periodicity of the system, the expanded stiffness function of the $i$ th meshing tooth pair is calculated at any time instant $t$ as

$k_{i}(t)=k\left[(\right.$ floor $\left.(\sigma)-i) t_{\mathrm{c}}+\bmod \left(t, t_{\mathrm{c}}\right)\right], \quad i=0,1, \ldots$, floor $(\sigma)$

The calculated $k_{0}(t)$ and $k_{1}(t)$ functions and their combined stiffness are shown in Fig. 5. It is noteworthy that $k_{0}(t)$ and $k_{1}(t)$ are, actually, different portions of $k(t)$ as described in Eq. (5). 


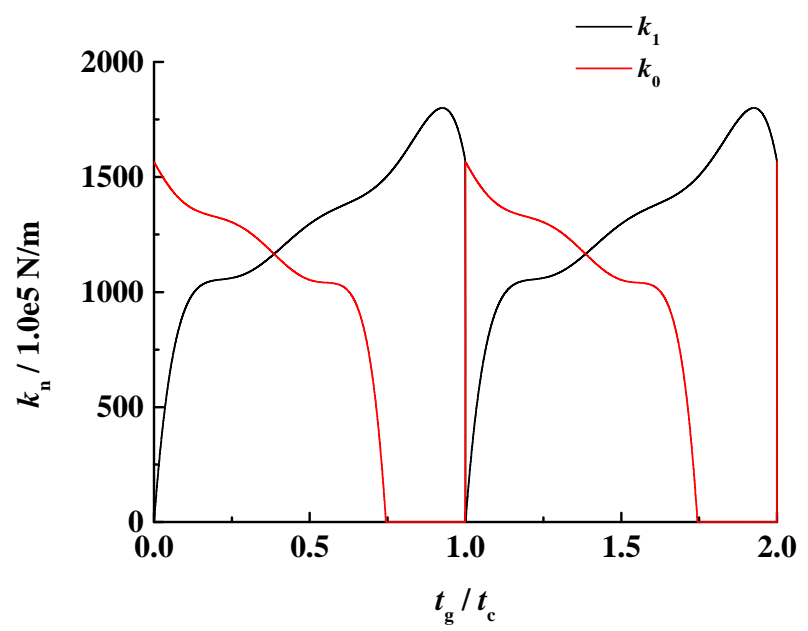

Fig. 5 Mesh stiffness of TIGs

\subsection{Six degree-of-freedom model with friction}

A six-degree-of-freedom (6-DOF) model is established as displayed in Fig. 6.

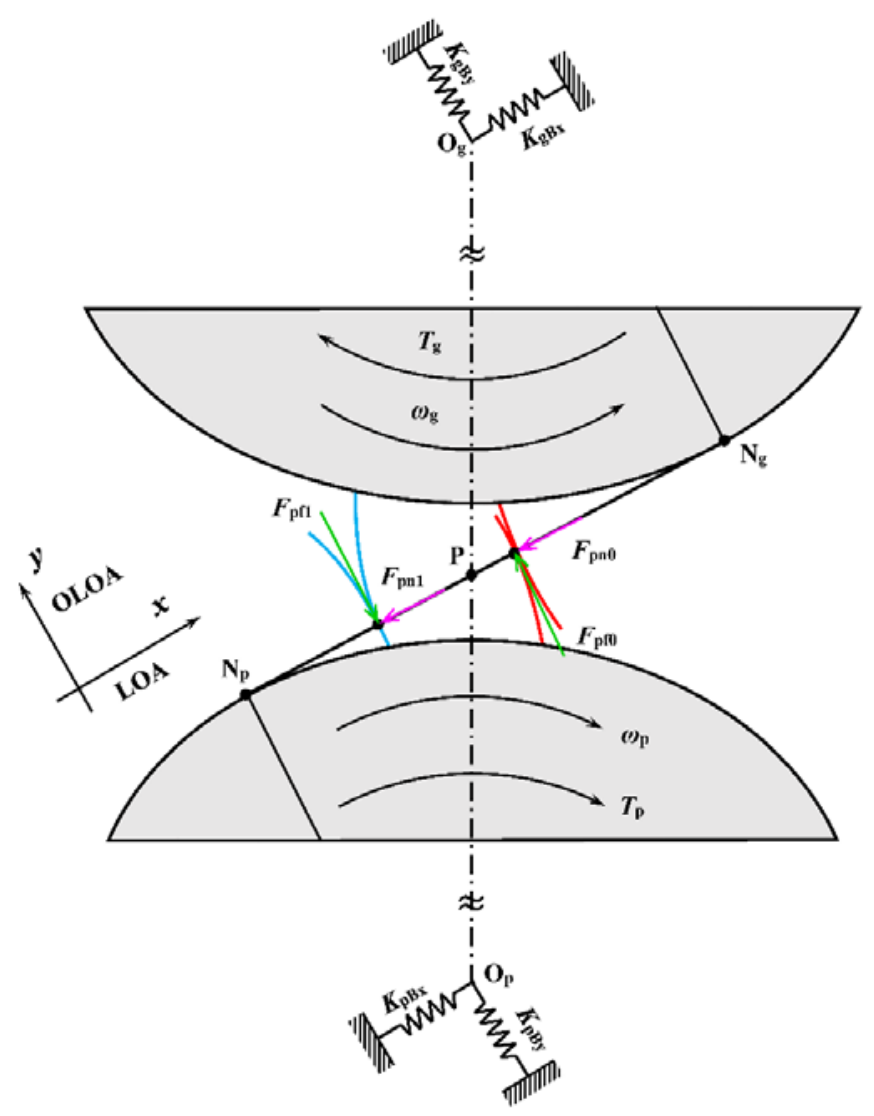

Fig. 6. 6-DOF model of TIGs

In the light of the Coulomb friction law, the magnitude of friction force is proportional to the normal tooth load as follows

$F_{\mathrm{fi}}=\left|\mu_{i} F_{\mathrm{n} i}\right|$

(6) 
The direction of $F_{\mathrm{fi}}$ depends on the sign of nominal relative sliding velocity. The moment arm for the friction force of pinion acting on the ith meshing tooth pair is given by $X_{\mathrm{p} i}(t)=\overline{\mathrm{N}_{\mathrm{p}} \mathrm{B}_{\mathrm{g}}}+($ floor $(\sigma)-i) \lambda+\bmod \left(\omega_{\mathrm{p}} r_{\mathrm{bp}} t, \lambda\right), \quad i=0,1, \cdots$, floor $(\sigma)$

The corresponding moment arm for the friction force of the gear is $X_{\mathrm{gi}}(t)=\overline{\mathrm{N}_{\mathrm{g}} \mathrm{C}_{\mathrm{g}}}+i \lambda-\bmod \left(\omega_{\mathrm{g}} r_{\mathrm{bg}} t, \lambda\right), \quad i=0,1, \cdots$, floor $(\sigma)$

(8)

Where "mod"' is the modulus function defined as $\bmod (x, y)=x-y$. floor $(x / y), \quad$ if $y \neq 0$.

Assume that the mesh damping coefficient $c_{i}(t)$, related to mesh stiffness $k_{i}(t)$ by a time-invariant damping ratio $\xi_{\mathrm{m} i}$ as follows

$c_{i}(t)=2 \xi_{\mathrm{m} i} \sqrt{k_{i}(t) \cdot I_{\mathrm{e}}}, \quad i=0,1, \cdots$, floor $(\sigma)$

where $I_{\mathrm{e}}=I_{\mathrm{p}} I_{\mathrm{g}} /\left(I_{\mathrm{p}} r_{\mathrm{bg}}^{2}+I_{\mathrm{g}} r_{\mathrm{bp}}^{2}\right)$.

The normal load acting on the tooth are

$F_{\mathrm{pni}}(t)=F_{\mathrm{gni}}(t)=k_{i}(t) \delta(t)+c_{i}(t) \dot{\delta}(t) \quad i=0,1, \cdots$, floor $(\sigma)$

(10)

where

$\delta(t)=r_{\mathrm{bp}} \theta_{\mathrm{p}}-r_{\mathrm{bg}} \theta_{\mathrm{g}}+x_{\mathrm{p}}-x_{\mathrm{g}}-\varepsilon_{\mathrm{s}}$

where $\varepsilon_{\mathrm{s}}(t)=e_{\mathrm{s}} \cos \left(\omega t+\varphi_{0}\right) ; \quad \omega=\omega_{\mathrm{p}} Z_{\mathrm{p}} / 2 \pi$.

The dynamic transmission error (DTE) is defined as follows

$\varepsilon_{\mathrm{d}}=r_{\mathrm{bp}} \theta_{\mathrm{p}}-r_{\mathrm{bg}} \theta_{\mathrm{g}}+x_{\mathrm{p}}-x_{\mathrm{g}}$

For a generic gear whose $j$ th meshing pair passes through the pitch point within the mesh cycle, the friction forces in the ith meshing pair are formulated as follows:

$$
F_{\mathrm{pfi}}(t)= \begin{cases}\mu F_{\mathrm{pni}}(t) & i=0,1, \cdots, j-1 \\ \mu F_{\mathrm{pni}}(t) \operatorname{sgn}\left(\bmod \left(\omega_{\mathrm{bp}} r_{\mathrm{bp}} t, \lambda\right)+(\text { floor }(\sigma)-i) \lambda-\overline{\mathrm{B}_{\mathrm{g}} \mathrm{P}}\right) & i=j \\ -\mu F_{\mathrm{pni}}(t) & i=j, j+1, \cdots, \text { floor }(\sigma)\end{cases}
$$

$$
F_{\mathrm{gfi}}(t)= \begin{cases}\mu F_{\mathrm{gni}}(t) & i=0,1, \cdots, j-1 \\ \mu F_{\mathrm{gni}}(t) \operatorname{sgn}\left(\bmod \left(\omega_{\mathrm{bg}} r_{\mathrm{bg}} t, \lambda\right)+(\text { floor }(\sigma)-i) \lambda-\overline{\mathrm{B}_{\mathrm{g}} \mathrm{P}}\right) & i=j \\ -\mu F_{\mathrm{gni}}(t) & i=j, j+1, \cdots, \text { floor }(\sigma)\end{cases}
$$

The governing equations for the translational degree of freedoms (DOFs) in the LOA and 
OLOA direction are respectively

$$
\begin{aligned}
& m_{\mathrm{p}} \ddot{x}_{\mathrm{p}}(t)+2 \xi_{\mathrm{pBx}} \sqrt{K_{\mathrm{pBx}} m_{\mathrm{p}}} \dot{x}_{\mathrm{p}}(t)+K_{\mathrm{pBx}} x_{\mathrm{p}}(t)+\sum_{i=0}^{n=\text { floor }(\sigma)} F_{\mathrm{pni}}(t)=0 \\
& m_{\mathrm{g}} \ddot{x}_{\mathrm{g}}(t)+2 \xi_{\mathrm{gBx}} \sqrt{K_{\mathrm{gBx}} m_{\mathrm{g}}} \dot{x}_{\mathrm{g}}(t)+K_{\mathrm{gBx}} x_{\mathrm{g}}(t)+\sum_{i=0}^{n=\text { ffloor }(\sigma)} F_{\mathrm{gni}}(t)=0 \\
& m_{\mathrm{p}} \ddot{y}_{\mathrm{p}}(t)+2 \xi_{\mathrm{pBy}} \sqrt{K_{\mathrm{pBy}} m_{\mathrm{p}}} \dot{y}_{\mathrm{p}}(t)+K_{\mathrm{pBy}} y_{\mathrm{p}}(t)-\sum_{i=0}^{n=\text { floor }(\sigma)} F_{\mathrm{pfi}}(t)=0 \\
& m_{\mathrm{g}} \ddot{y}_{\mathrm{g}}(t)+2 \xi_{\mathrm{gBy}} \sqrt{K_{\mathrm{gBy}} m_{\mathrm{g}}} \dot{y}_{\mathrm{g}}(t)+K_{\mathrm{gBy}} y_{\mathrm{g}}(t)-\sum_{i=0}^{n=\text { flloor }(\sigma)} F_{\mathrm{gfi}}(t)=0
\end{aligned}
$$

The governing equations for the torsional DOFs are

$$
\begin{aligned}
& I_{\mathrm{p}} \ddot{\theta}_{\mathrm{p}}(t)-T_{\mathrm{p}}+r_{\mathrm{bp}} \sum_{i=0}^{n=\text { flloor }(\sigma)} F_{\mathrm{pni}}(t)-\sum_{i=0}^{n=\text { floor }(\sigma)} X_{\mathrm{pi}} F_{\mathrm{fpi}}(t)=0 \\
& I_{\mathrm{g}} \ddot{\theta}_{\mathrm{g}}(t)+T_{\mathrm{g}}-r_{\mathrm{bg}} \sum_{i=0}^{n=\text { floor }(\sigma)} F_{\mathrm{gni}}(t)-\sum_{i=0}^{n=\text { floor }(\sigma)} X_{\mathrm{g} i} F_{\mathrm{fg} i}(t)=0
\end{aligned}
$$

\subsection{Friction coefficient in elastohydrodynamic lubrication}

Normally gear transmissions work in the condition of mixed elastohydrodynamic lubrication (EHL). To simply the problem, the friction is only considered in the pure EHL. The friction coefficient varies as the gear teeth mesh, owning to continually changing lubrication conditions between the contacting teeth. $\mathrm{Xu}^{[12]}$ predicted the values of friction coefficient in EHL for about 10,000 cases for each lubricant of interest. These cases cover various combinations of parameters to implement a multiple linear regression analysis to yield a new friction coefficient formula as follows

$\mu=e^{f\left(s r, P_{h}, \eta_{0}, s\right)} P_{\mathrm{h}}^{b_{2}}|s r|^{b_{3}} v_{\mathrm{e}}^{b_{6}} \eta_{0}^{b_{2}} R^{b_{8}}$

$$
f\left(s r, P_{\mathrm{h}}, \eta_{0}, S\right)=b_{1}+b_{4}|s r| P_{\mathrm{h}} \log _{10}\left(\eta_{0}\right)+b_{5} e^{-|s r| P_{\mathrm{h}} \log _{10}\left(\eta_{0}\right)}+b_{9} e^{s}
$$

Where $P_{\mathrm{h}}=\sqrt{F_{n} E^{\prime} / 2 \pi R^{\prime}} ; s r=\frac{v_{\mathrm{s}}}{v_{\mathrm{e}}}$

Here $b_{i}(i=1,2, \ldots, 9)$ are constant coefficients that depend on the lubricant type. For the lubricant used in this study, a typical gear oil, $b_{i}=-8.92,1.03,1.04,-0.35,2.81,-0.10,0.75,-0.39$ and 0.62 for $i=1 \sim 9$, respectively. The effective radius of curvature $R^{\prime}$ needs to be calculated according to the results of TCA.

\section{Model validation}

To verify the above 6-DOF model of TIG, the results of normal contact loads and angular velocity are compared with those using the approach of multi-body dynamics (MBD). In reference [13] the multi-body model of the TIG was verified indirectly by an impact 
experiment. So we use it to verify the 6-DOF model here. The parameters of a TIG set are shown in Tab.2. The constant angular velocity of pinion is $2 \pi \mathrm{rad} / \mathrm{s}$, and the resisting moment is $20 \mathrm{~N} \cdot \mathrm{m}$. The governing equations of 6-DOF system model are numerically integrated through a 4th-5th order Runge-Kutta algorithm with a fixed time step.

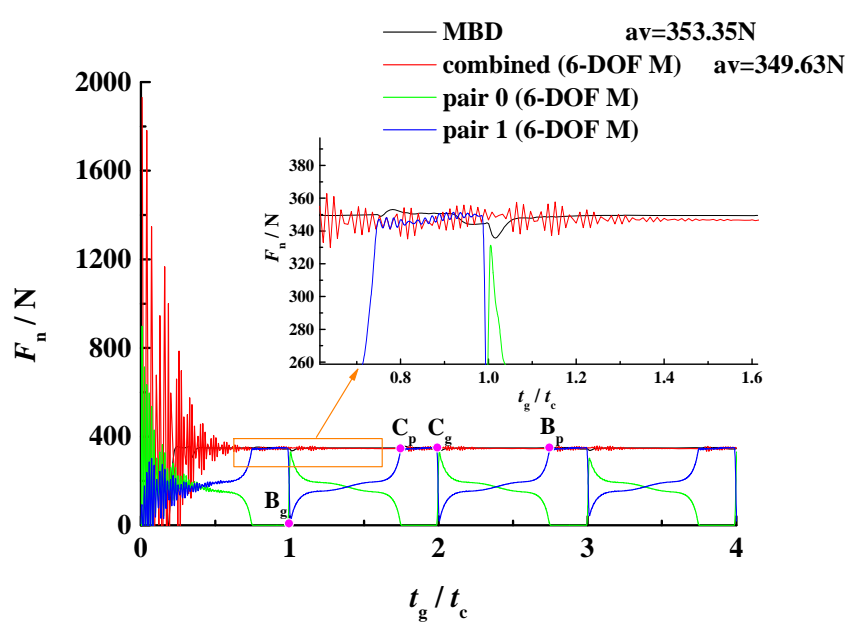

Fig.7. Normal contact force of two models

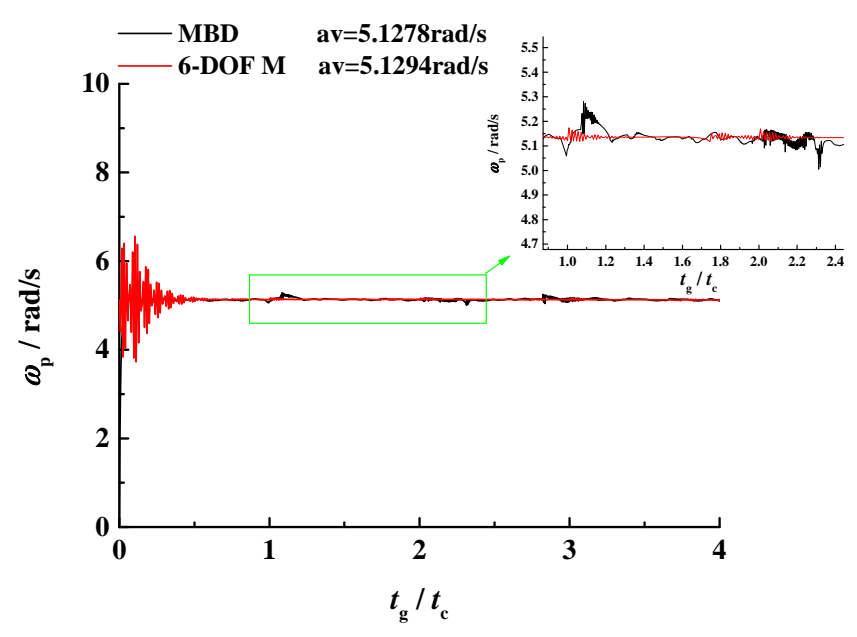

Fig.8. Angular velocity of gear

Fig. 7 shows the normal contact load of two models. Without friction forces, the normal contact force is $F_{\mathrm{n}}=T_{2} / r_{\mathrm{b} 2}=20 / 0.05756=347.49 \mathrm{~N}$, and the average value of our model is $349.63 \mathrm{~N}$. The increase in average normal contact force is induced by impacts during meshing in and out as well as friction forces. Besides, at points $\mathrm{B}_{\mathrm{g}}, \mathrm{C}_{\mathrm{p}}, \mathrm{C}_{\mathrm{g}}$ and $\mathrm{B}_{\mathrm{p}}$, corner contacts are observed for $F_{\mathrm{n}}$, corresponding to the time instants when meshing tooth pairs come into or out of contact. Fig.8. displays the angular velocity of gear. The theoretical angular velocity is $\omega_{\mathrm{g}}=2 \pi \times 40 / 49=5.1291 \mathrm{rad} / \mathrm{s}$. In spite of fluctuation, the average value of our model is very 
close to the theoretical one.

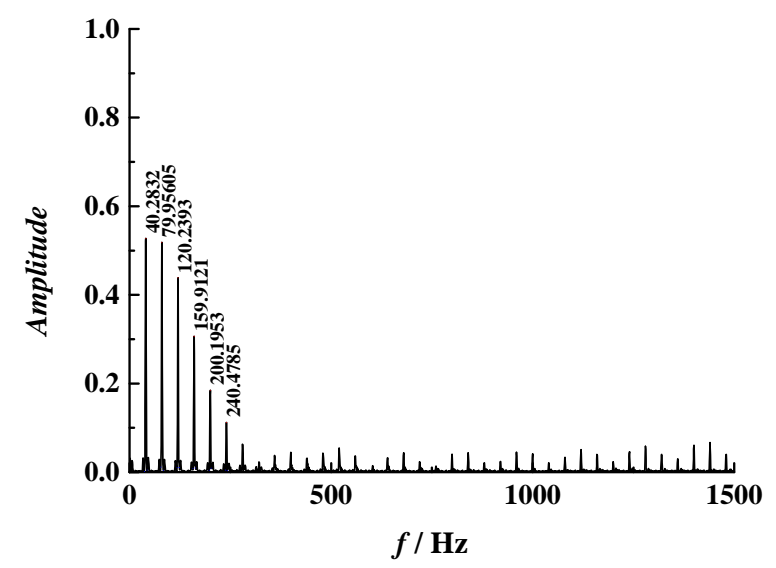

Fig.9. Frequency Analysis of normal contact force

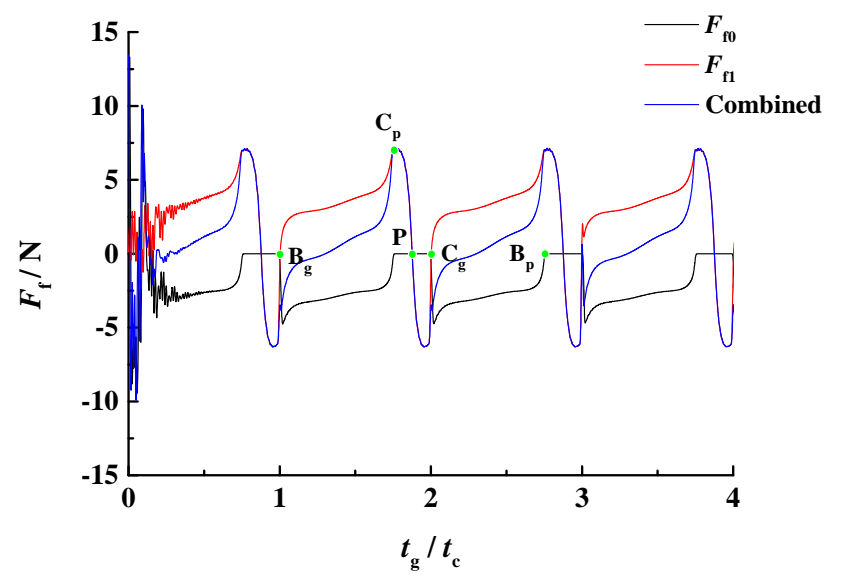

Fig.10. Sliding friction forces over meshing

Frequency-domain analysis for normal contact force is shown in Fig. 9. From the figure the primary resonances is found at $40.28 \mathrm{~Hz}$, nearly equal to gear mesh frequency ( $2 \pi Z_{\mathrm{p}} / \omega_{\mathrm{p}}$ ), which is associated with a mode having the LOA transverse motions and the torsional motions of the wheels. Fig.10 shows the sliding friction forces for pair \#0, pair \#1 and the combined one. The figure can reflect all of the key meshing events.

\section{Results and discussion}

A numerical example is provided according to parameters in Tab. 2. In order to study the dynamic performance of TIGs comprehensively, six operation conditions are set in Tab. 3, ranging from low-speed to high-speed, and from light-load to heavy-load. Also a model of a standard involute gear (SIG) pair is built with the same parameters. Specifically, normal module, pressure angle, tooth number and parameters of inertial properties are kept 
unchanged.

Tab. 2. Parameters for a TIG set

\begin{tabular}{ccc}
\hline & pinion & gear \\
\hline normal module (mm) & 2.5 & 2.5 \\
pressure angle (deg) & 20 & 20 \\
tooth number & 40 & 49 \\
reference torus radius (mm) & 35 & 55 \\
pitch circle radius (mm) & 50 & 61.25 \\
face width (mm) & 15 & 20 \\
deviation of torus center (mm) & 15 & 116.25 \\
Poisson ratio & \multicolumn{2}{c}{0.3} \\
Young's modulus (N/mm $\left.{ }^{2}\right)$ & \multicolumn{2}{c}{$2.06 \mathrm{e} 5$} \\
amplitude of STE (m) & \multicolumn{2}{c}{$1.0 \mathrm{e}-5$} \\
\hline
\end{tabular}

\begin{tabular}{ccc}
\hline condition & $\omega_{\mathrm{p}}(\mathrm{rad} / \mathrm{s})$ & $T_{\mathrm{g}}(\mathrm{N} \cdot \mathrm{m})$ \\
\hline$\# 1$ & 10 & 49 \\
$\# 2$ & 10 & 245 \\
$\# 3$ & 100 & 49 \\
$\# 4$ & 100 & 245 \\
$\# 5$ & 300 & 49 \\
$\# 6$ & 300 & 245 \\
\hline
\end{tabular}

Tab. 3. Operation conditions of a TIG set

\subsection{Dynamic transmission error}

The dynamic transmission error (DTE) is the important index used to characterize transmission accuracy of a gear drive. The DTE of two models are shown in Fig.11 13 and Tab.4. It can be seen from them that whether trend or magnitude, the results of two types of gear drive are almost the same. It is noteworthy that the resisting moment has a greater effect on the DTE than the angular velocity. To be specific, the amplitude of DTE increases along with the increase of the resisting moment.

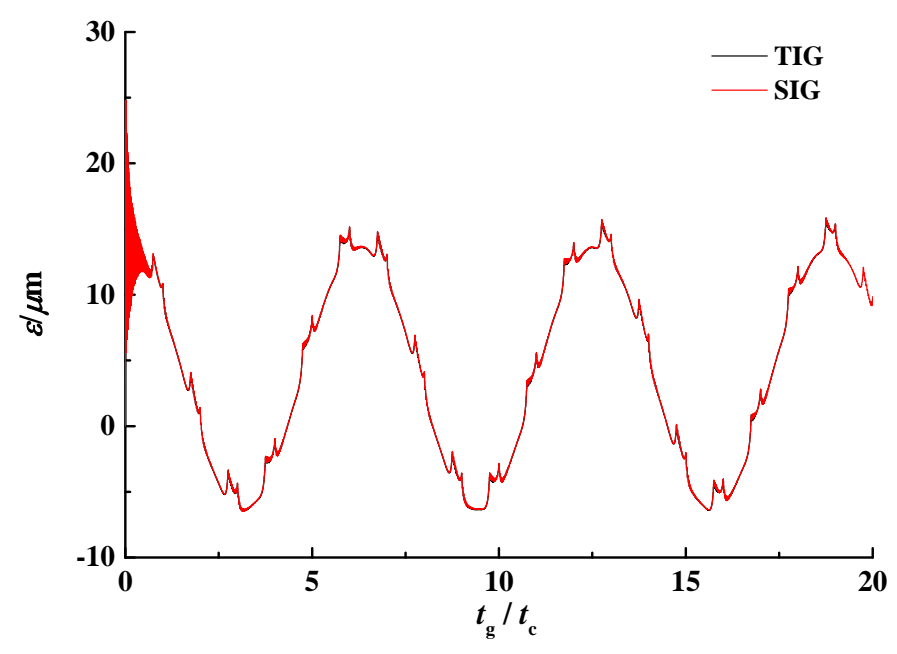

Fig.11. DTE in condition \#1 


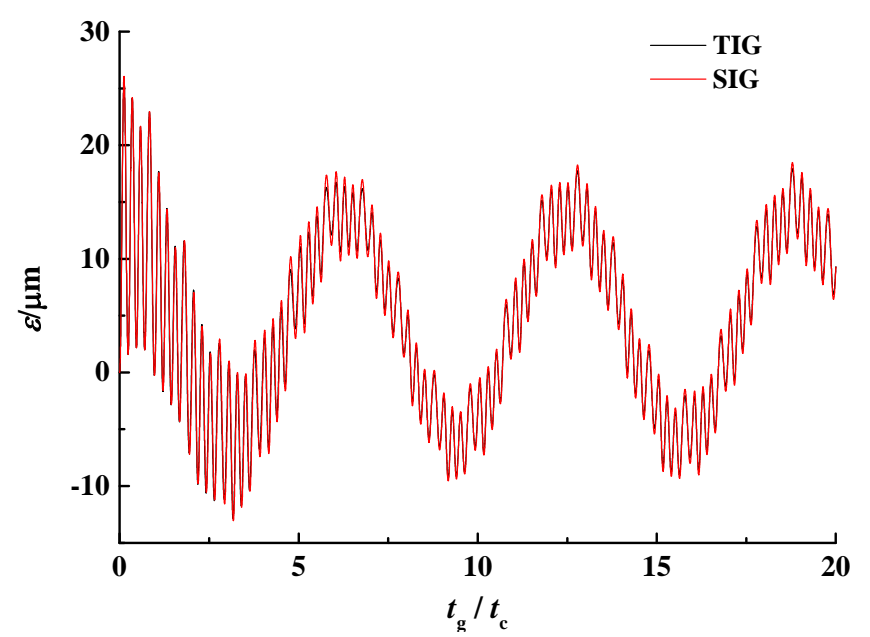

Fig.12. DTE in condition \#3

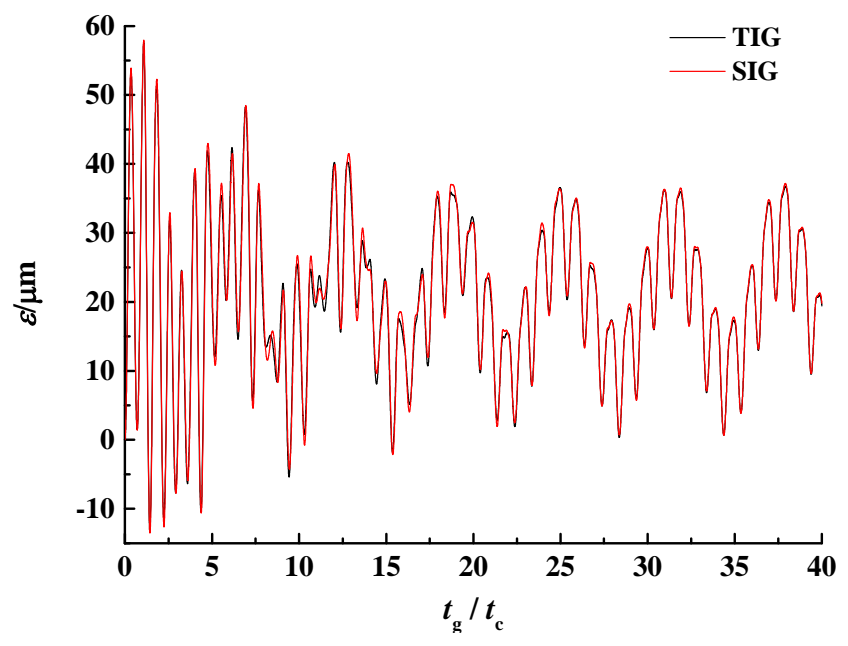

Fig.13. DTE in condition \#6

Tab. 4. Maximum

DTE

\begin{tabular}{|c|c|c|c|c|}
\hline \multirow{2}{*}{ condition } & \multicolumn{2}{|c|}{ Max of $\varepsilon_{\mathrm{d}}(\mu \mathrm{m})$} & \multicolumn{2}{|c|}{ Min of $\varepsilon_{\mathrm{d}}(\mu \mathrm{m})$} \\
\hline & TIG & SIG & TIG & SIG \\
\hline$\# 1$ & 28.7453 & 28.8583 & -6.5421 & -6.5824 \\
\hline$\# 2$ & 67.9565 & 68.5789 & 0.0000 & 0.0000 \\
\hline \#3 & 26.0776 & 26.1188 & -12.9003 & -13.0756 \\
\hline$\# 4$ & 61.9691 & 62.5844 & -16.3022 & -17.8649 \\
\hline$\# 5$ & 25.7425 & 25.7837 & -15.0341 & -14.9987 \\
\hline \#6 & 57.6970 & 58.0223 & -13.5303 & -13.6643 \\
\hline
\end{tabular}

and minimum of

\subsection{Sliding friction forces}

Fig.14 16 display the sliding friction forces of pair \#0 and pair \#1. The average value of magnitude of combined sliding forces are given in Tab. 5. It can be seen from the figures that 
the general trends of SIG and TIG are not identical. The possible reason is that the contact patterns of two types of gears are totally dissimilar, which makes the friction coefficient vary differently with contact point. Besides, the disparity of magnitude of sliding friction forces are mainly dependent on the resisting moment. According to Tab.5, under the light load, the TIG has a somewhat larger average sliding friction force than SIG. But in the case of heavy load, the situation reverses: the SIG has a much larger mean sliding friction force than does TIG.

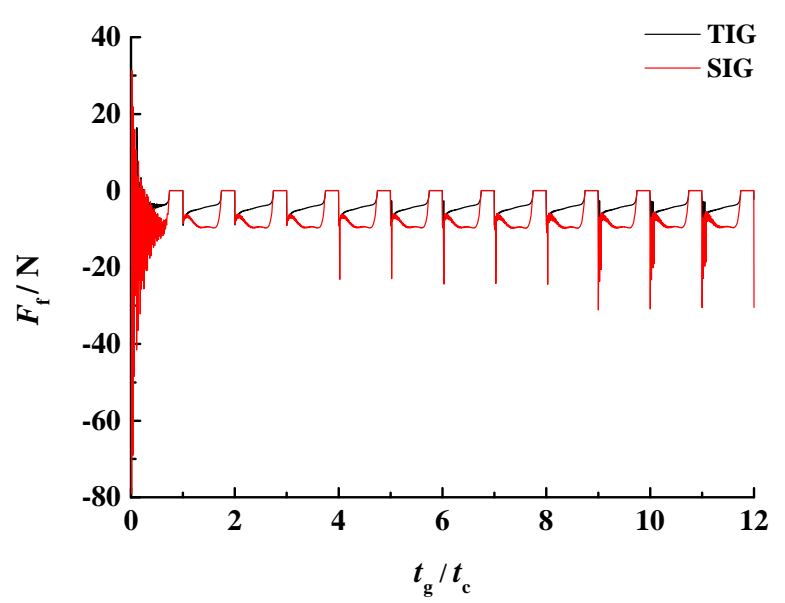

a) Pair 0\#

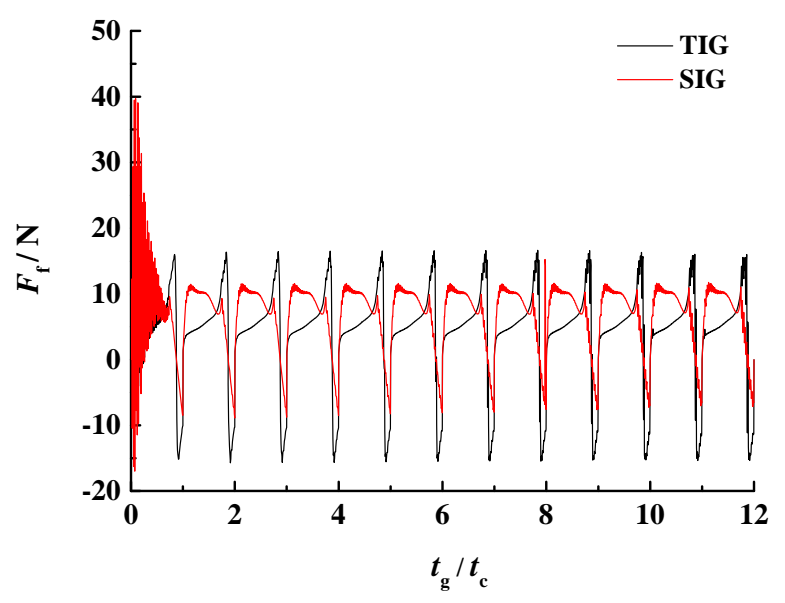

b) Pair 1\#

Fig.14. Sliding friction force in condition \#1 


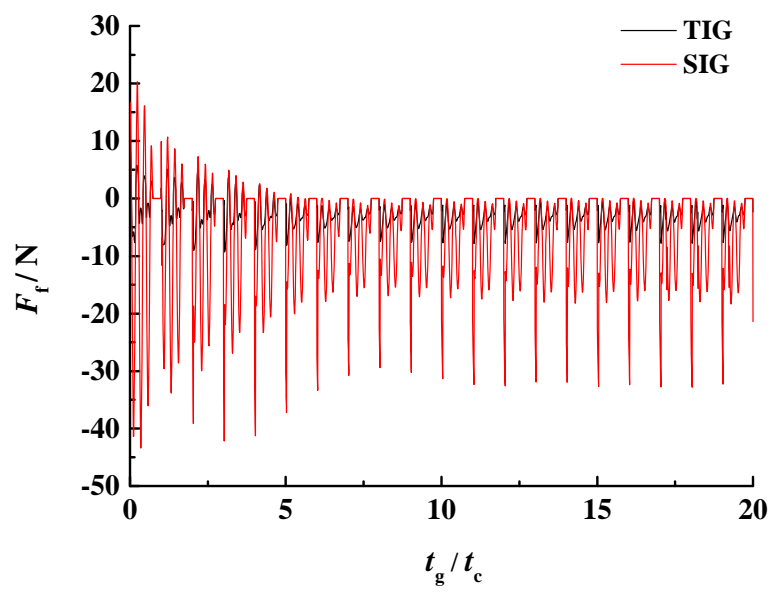

a) Pair 0\#

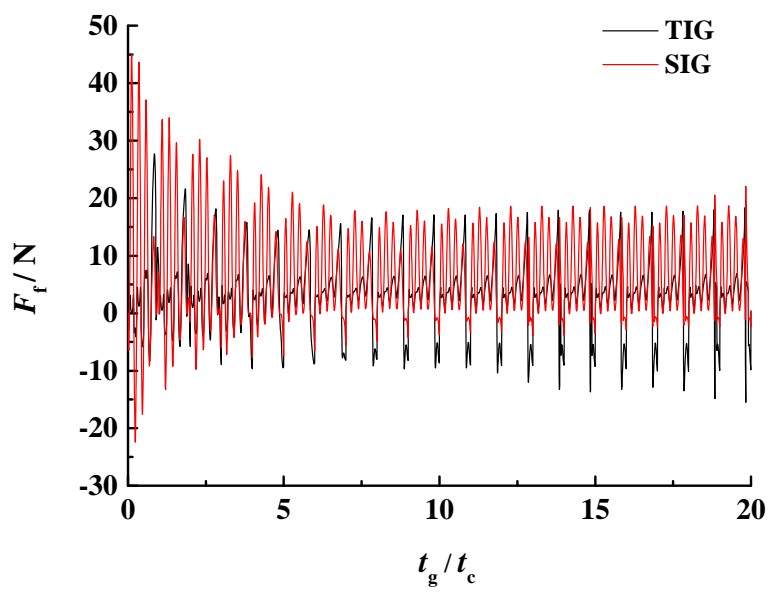

b) Pair 1\#

Fig.15. Sliding friction force in condition \#3

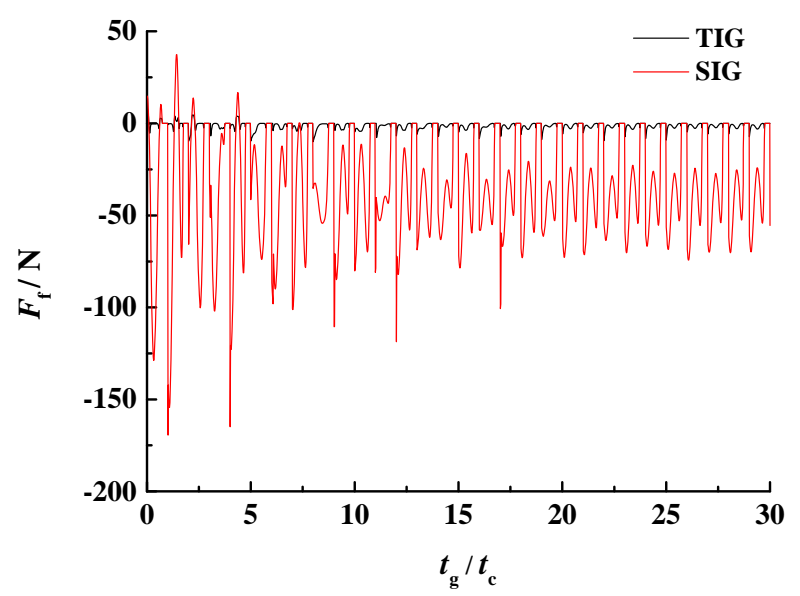

a) Pair 0\# 


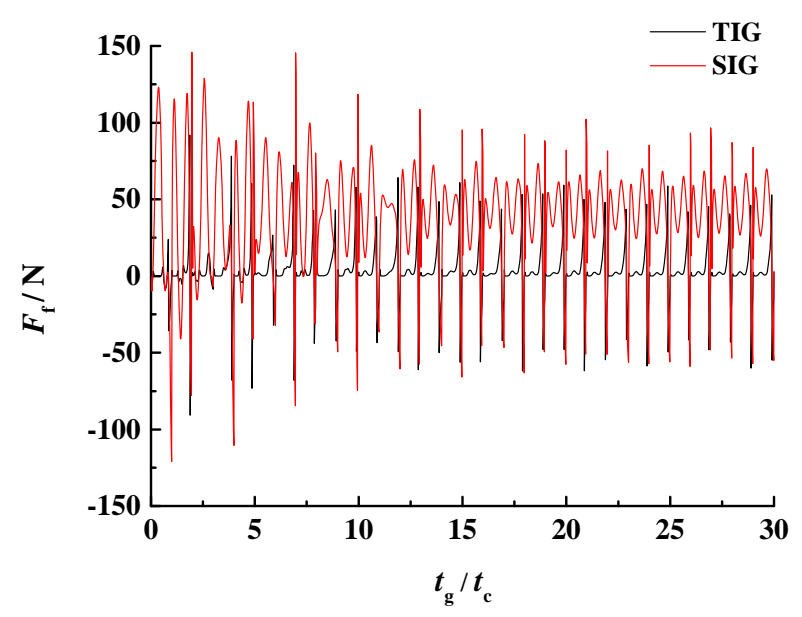

b) Pair 1\#

Fig.16. Sliding friction force in condition \#6

Tab. 5. Average value of combined sliding friction forces

\begin{tabular}{ccc}
\hline \multirow{2}{*}{ condition } & \multicolumn{2}{c}{$\begin{array}{c}\text { Ave of combined sliding } \\
\text { friction force (N) }\end{array}$} \\
\cline { 2 - 3 } & TIG & SIG \\
\hline$\# 1$ & 4.8461 & 3.1853 \\
$\# 2$ & 9.0038 & 33.3825 \\
$\# 3$ & 3.6535 & 3.6369 \\
$\# 4$ & 5.6076 & 32.2601 \\
$\# 5$ & 3.6686 & 2.1687 \\
$\# 6$ & 7.1076 & 21.0416 \\
\hline
\end{tabular}

\subsection{Mechanical efficiency of gear pair}

Efficiency losses in a gearbox originate from several sources: Gear mesh sliding friction, rolling friction, windage, oil churning, and bearing friction ${ }^{[14]}$. Once gears are loaded, the contact experiences combined sliding and rolling, both of which cause frictional losses. If only frictional losses are counted in, the instantaneous output power can be expressed as the difference between the input power and the frictional power losses. With this, the mechanical efficiency (ME) of gear pair can be determined using the approach by $\mathrm{Xu}^{[15]}$ as follows

$\chi=1-\frac{1}{T_{\mathrm{p}} \omega_{\mathrm{p}}} \sum_{i=1}^{n}\left[\left|F_{\mathrm{pfi}}\left(v_{\mathrm{p}}-v_{\mathrm{g}}\right)\right|+\left|F_{\mathrm{pri}}\left(v_{\mathrm{p}}+v_{\mathrm{g}}\right)\right|\right]$

The rolling friction force of the pinion can be estimated by utilizing a published empirical formula ${ }^{[16]}$ as

$F_{\text {pri }}=4.318(G U)^{0.658} W^{0.0126} R^{\prime} / \alpha$

The results of ME for TIG and SIG are displayed in Fig.17 20 and Tab.6. From the 
figures, the general trend of transient ME for two gear pairs are similar, and the increase in angular velocity tends to cause fluctuation of ME. It can be seen from the table, as the angular velocity increases, both of the ME decrease. But they increase with the increasing of resisting moment. When a light load is imposed on the gear, the ME of SIG is slightly higher than TIG. However, TIG has a higher ME than SIG when a heavy load is applied. The reason for this can be found in their sliding friction forces.

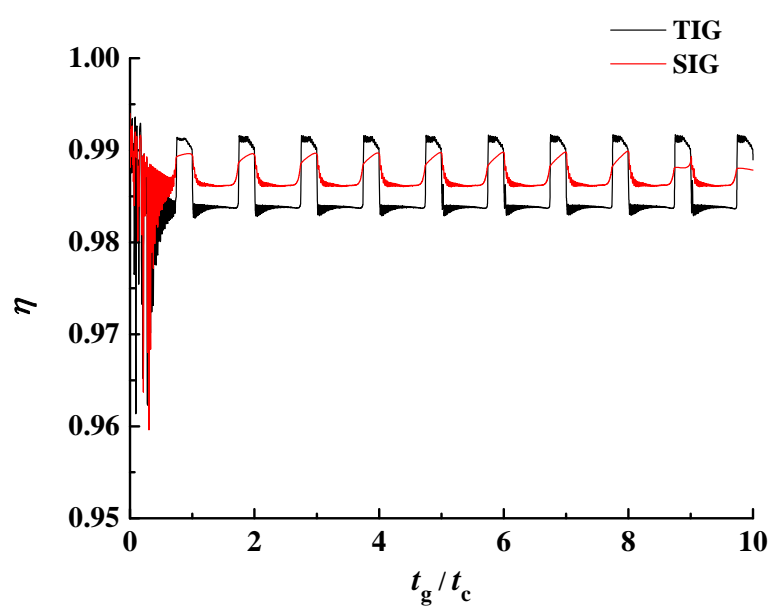

Fig. 17. ME in condition \#1

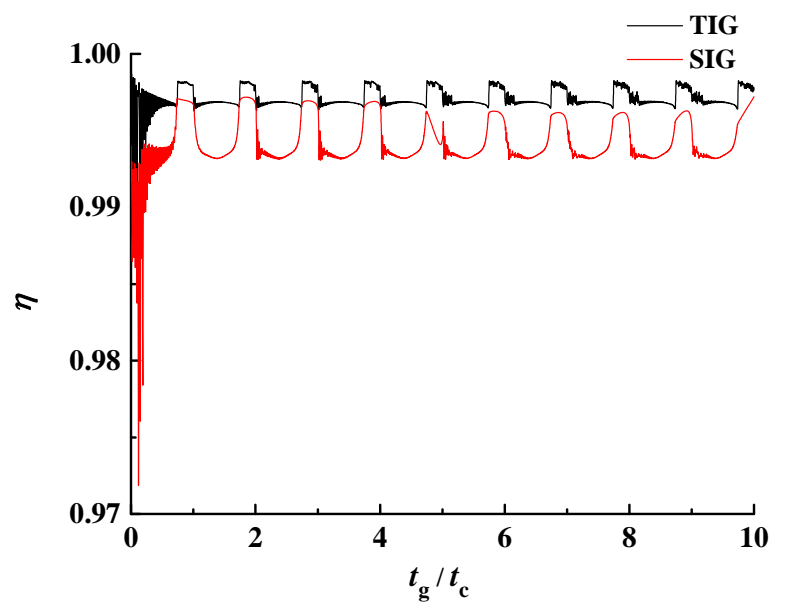

Fig. 18. ME in condition \#2 


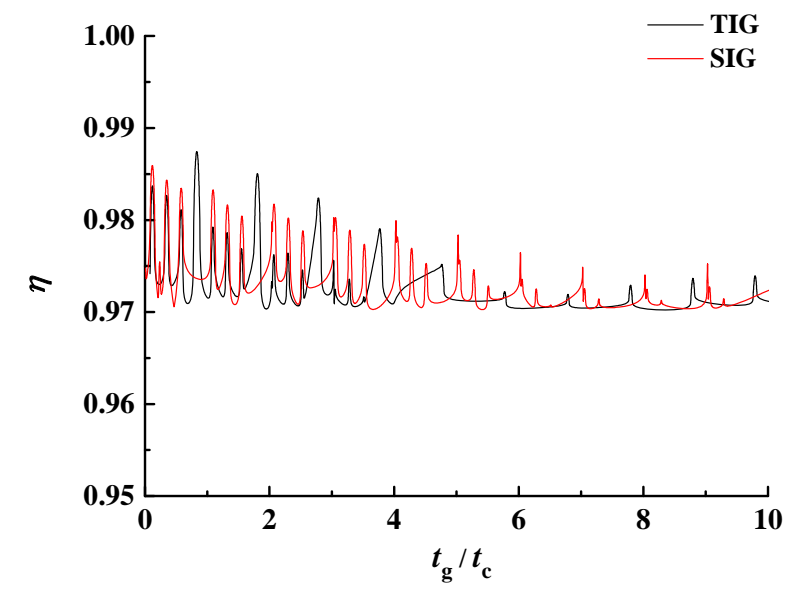

Fig. 19. ME in condition \#3

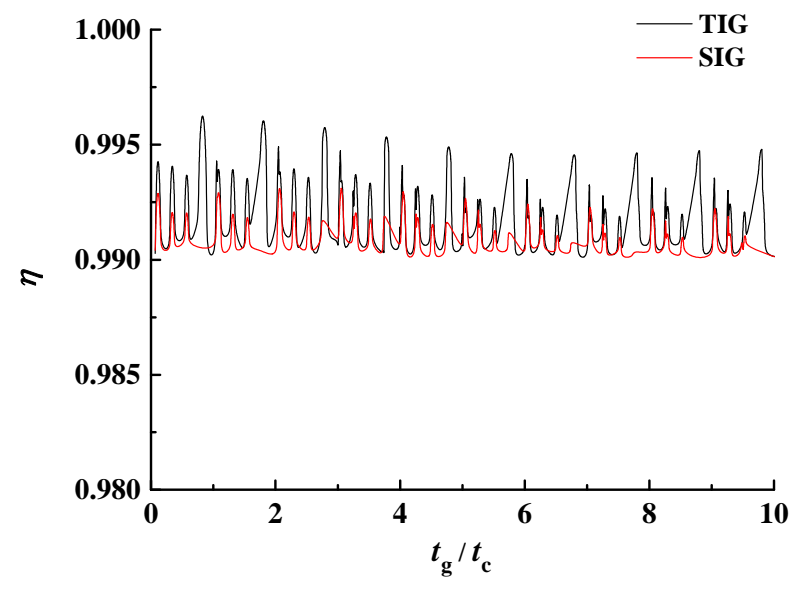

Fig. 20. ME in condition \#4

Tab. 6. Average value of ME

\begin{tabular}{ccc}
\hline \multirow{2}{*}{ condition } & \multicolumn{2}{c}{ Ave of ME } \\
\cline { 2 - 3 } & TIG & SIG \\
\hline$\# 1$ & 0.9857 & 0.9865 \\
$\# 2$ & 0.9971 & 0.9935 \\
$\# 3$ & 0.9739 & 0.9744 \\
$\# 4$ & 0.9925 & 0.9913 \\
$\# 5$ & 0.9602 & 0.9608 \\
$\# 6$ & 0.9841 & 0.9824 \\
\hline
\end{tabular}

\subsection{Minimum film thickness of lubrication oil}

In order to get a preliminary understanding of the lubrication property, the minimum film thickness of SIG and TIG are computed employing Dowson \& Higginson Formula ${ }^{[17]}$. Due to 
point contact, the formula for elliptical contact applies to TIG as follows

$h_{\min }=3.63 G^{0.49} U^{0.68} W^{-0.073}\left(1-e^{-0.68 \kappa}\right) R^{\prime}$

(25)

The minimum film thickness of SIG is given by

$h_{\min }=1.6 G^{0.6} U^{0.7} W^{-0.13} R^{\prime}$

The results of pair \#0 and pair \#1 are shown in Fig. 21 23 and Tab.7. From the figures and table we can see that the minimum film thickness of TIG is higher than that of SIG in all operation conditions. The variation trend of $h_{\min }$ over a whole mesh cycle is also different from each other. Essentially, the differences in $h_{\min }$ are incurred by the contact pattern of gears. Especially convex-concave contact makes the effective radius of curvature of TIG much larger than that of SIG.

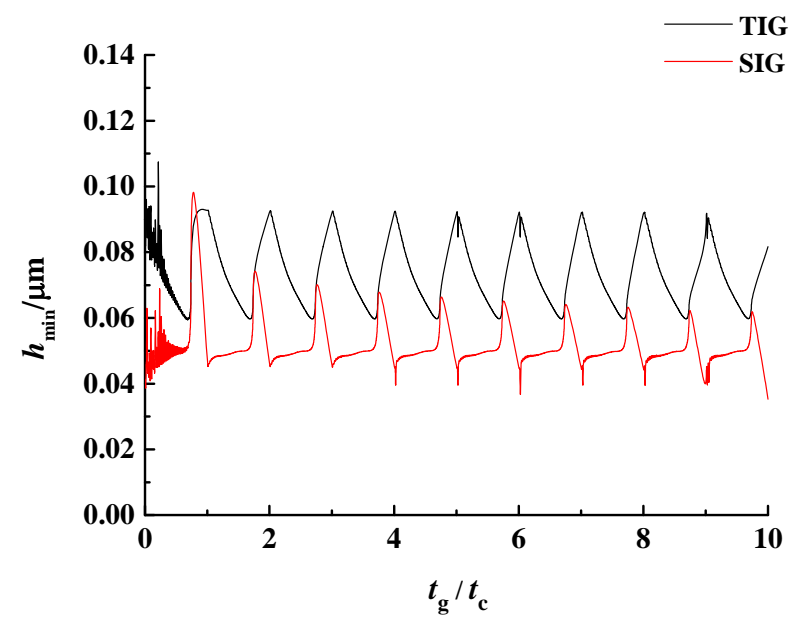

a) Pair \#0

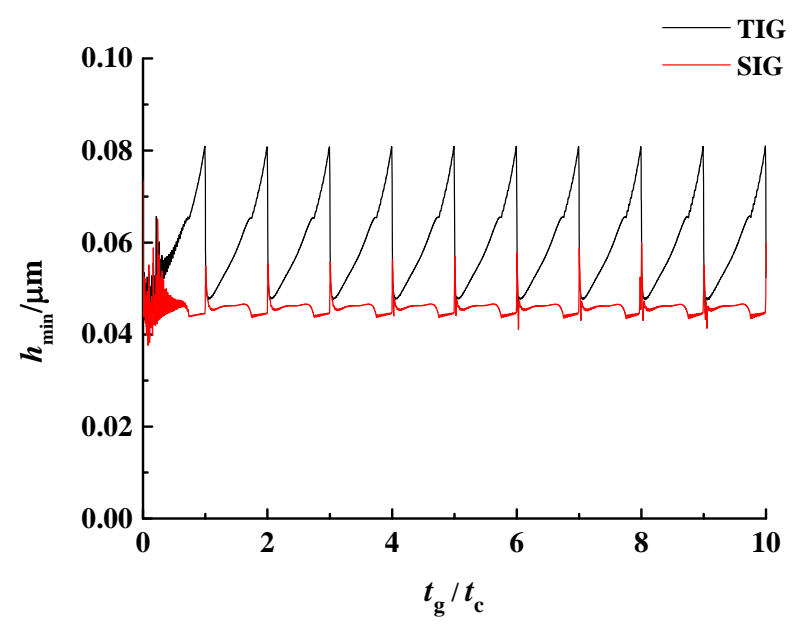

b) Pair \#1

Fig. 21. Minimum film thickness in condition \#1 


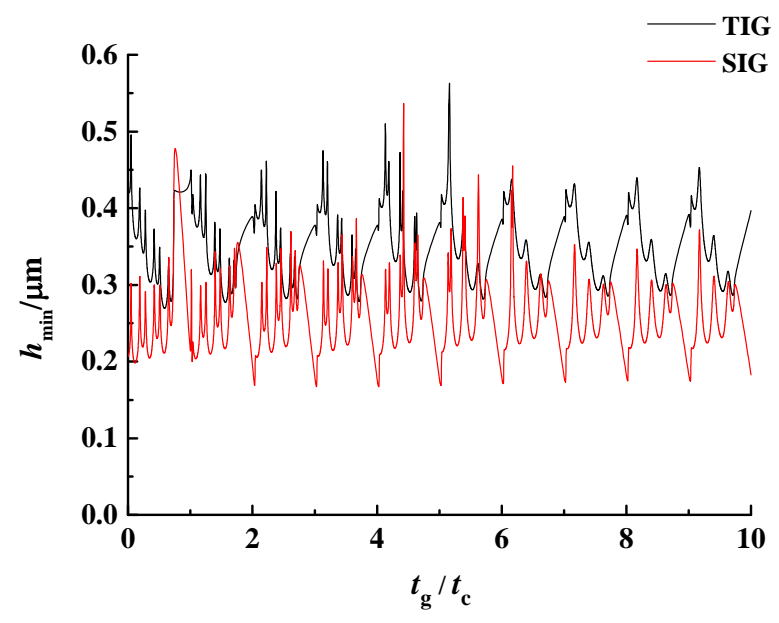

a) Pair \#0

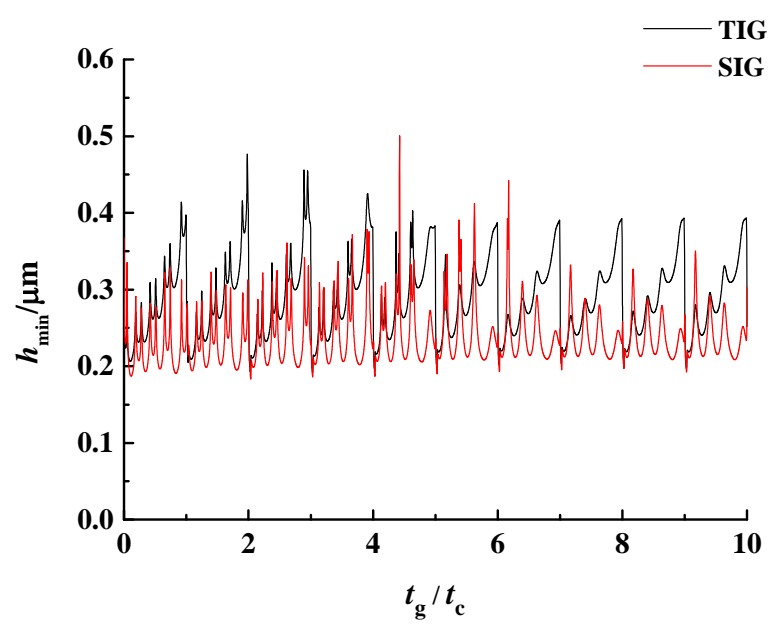

b) Pair \#1

Fig. 22. Minimum film thickness in condition \#3

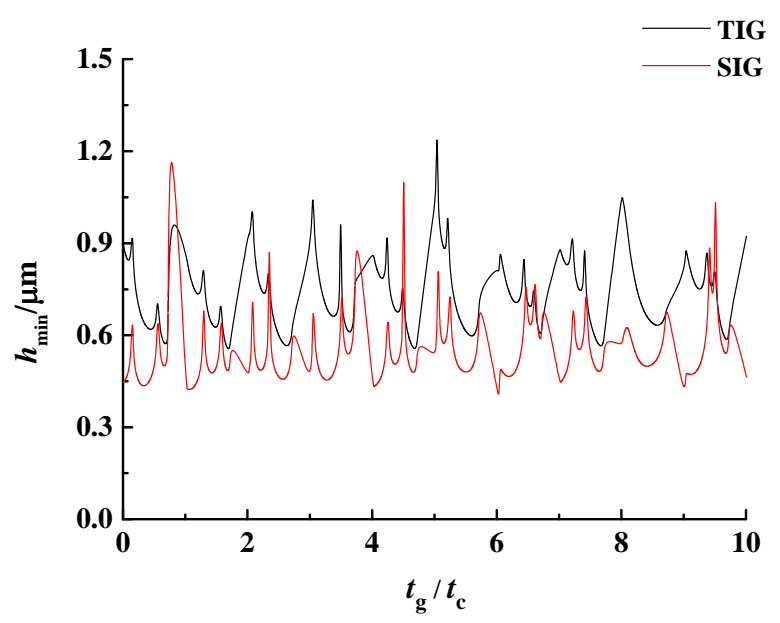

a) Pair 0\# 


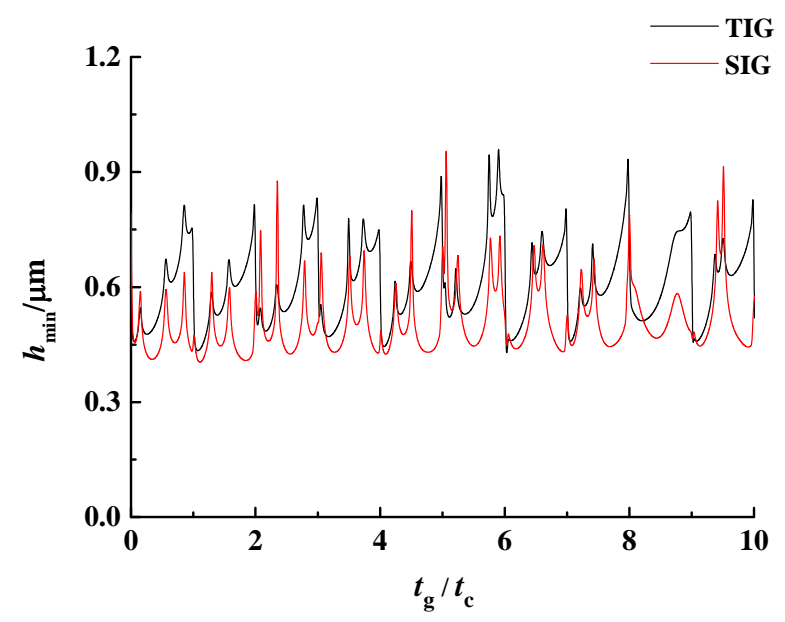

b) Pair 1\#

Fig. 23. Minimum film thickness in condition \#5

Tab. 7. Average value of minimum film thickness

\begin{tabular}{ccccc}
\hline \multirow{2}{*}{ condition } & \multicolumn{2}{c}{$\begin{array}{c}\text { Ave of min film thickness } \\
\text { of pair } 0(\mu \mathrm{m})\end{array}$} & \multicolumn{2}{c}{$\begin{array}{c}\text { Ave of min film } \\
\text { thickness of pair } 1(\mu \mathrm{m})\end{array}$} \\
\cline { 2 - 5 } & TIG & SIG & TIG & SIG \\
\hline$\# 1$ & 0.07183 & 0.04927 & 0.05971 & 0.04575 \\
$\# 2$ & 0.06330 & 0.03942 & 0.05338 & 0.03732 \\
$\# 3$ & 0.34560 & 0.25644 & 0.29000 & 0.23957 \\
$\# 4$ & 0.30650 & 0.20857 & 0.26015 & 0.19709 \\
$\# 5$ & 0.72902 & 0.53948 & 0.60704 & 0.50160 \\
$\# 6$ & 0.64816 & 0.51400 & 0.54233 & 0.40909 \\
\hline
\end{tabular}

\section{Conclusion}

Based on the previous studies of mesh principle, a multi-degree-of-freedom dynamics model of the TIG pair with realistic time-varying stiffness is built, including effects of sliding friction and alternate meshing of single-double tooth pairs. In six cases, the DTE, ME, sliding friction forces and minimum oil-film thickness of TIG are calculated and compared with those of SIG. It can be concluded from above analysis as follows

1. Although the complexity of tooth shape is increased, the TIG pair still nearly has the same transmission accuracy as SIG.

2. Unlike the SIG, the TIG pair works on convex-concave-point-contact, which leads to the discrepancies in sliding friction forces and transient ME. However, there is little difference in average ME of two types of gear pairs.

3. The contact pattern makes the TIG pair have a higher minimum oil-film thickness, which 
shows that it exhibits a better performance in lubrication condition.

\section{Acknowledgment}

This work is supported by "the Fundamental Research Funds for the Central Universities", NO. NS2016049.

\section{Reference}

[1] Liu, L., Huang, Y. H., Tian, Z. J., Shen, L. D., and Liu, Z. D. A type of concave or convex torus involute gear and its design and manufacture method [P]. Chinese patent no. : 201210081587.4

[2] Liu, L., Tan, J. W., and Fang, M. J. Geometry and contact characteristics of torus involute gears [J]. Proceedings of the Institution of Mechanical Engineers, Part E:Journal of Process Mechanical Engineering, published online, DOI: 10.1177/0954408915591718

[3] Li, S.,and Kahraman, A. A spur gear mesh interface damping model based on elastohydrodynamic contact behavior [J]. International Journal of Powertrains, 2011,1(1):4-21

[4] Houser, D. R., Vaishya, M., and Sorenson, J. D. Vibro-acoustic effects of friction in gears: an experimental investigation [C]. SAE 2001 Noise \& Vibration Conference \& Exposition, 2001-01-1516.

[5] Velex, P., and Sainsot, P. An analytical study of teeth friction excitations in errorless spur and helical gears [J]. Mechanism and Machine Theory, 2002, 37(7):641-658.

[6] Vaishya, M., and Singh, R. Strategies for modeling friction in gear dynamics [J]. ASME Journal of Mechanical Design, 2003,125: 383-393.

[7] Song, H., Gunda, R., and Singh, R. Effect of sliding friction on the dynamics of spur gear pair with realistic time-varying stiffness [J]. Journal of Sound and Vibration, 2007, 301(3):927-949.

[8] Song, H., Gunda, R., and Singh, R. Inclusion of sliding friction in contact dynamics model for helical gears [J]. ASME Journal of Mechanical Design, 2007, 129:48-57.

[9] Kelley, B. W., and Lemanski, A. J. Lubrication of involute gearing [J]. Proceedings of the Institution of Mechanical Engineers, Conference Proceedings, September, 1967, 182(1):173-184

[10] Feng, Z. H., Wang, S. L., Lim,T. C., and Peng, T. Enhanced friction model for high-speed right-angle gear dynamics [J]. Journal of Mechanical Science and Technology, 2011,25 (11):2741-2753

[11] Wang, C., and Shi, Z. Y. A dynamic calculation method of sliding friction losses for a helical gear pair [J]. Journal of the Brazilian Society of Mechanical Sciences and Engineering, 2016,7, DOI 10.1007/s40430-016-0585-8

[12] Xu, H., and Kahraman, A. Prediction of friction-related power losses of hypoid gear pairs [J]. Proceedings of the Institution of Mechanical Engineers, Part K: Journal of Multi-body Dynamics, 2007,221 (3): 387-400

[13] Liu, L., and Tan, J. W. Dynamic analysis of torus involute gear including transient elastohydrodynamic effects[J]. Journal of Vibroengineering, 2016, 18(7):4222-4236

[14] Heingartner, P., and Mba, D. Determining Power Losses in The Helical Gear Mesh; Case Study. Proceeding of DETC’3, ASME 2003 Design Engineering Technical Conferences and Computers 
and Information in Engineering Conference, Chicago, Illinois,2003

[15] Xu, H., Kahraman, A., Anderson, N. E., and Maddock, D. G. Prediction of Mechanical Efficiency of Parallel-Axis Gear Pairs [J]. Transactions of the ASME, Journal of Mechanical Design, 2007, 129 (1):58-68

[16] Wu, S., and Cheng, H. S. A Friction Model of Partial-EHL Contacts and its Application to Power Loss in Spur Gears [J]. Tribology Transaction, 1991, 34 :398-407

[17] Dowson, D. and Higginson, G. R. A numerical solution to the elastohydrodynamic problem. J. Mech. Eng. Sci., 1959, 1, 6 